\title{
BMJ Open Estimation of the economic burden of COVID-19 using disability-adjusted life years (DALYs) and productivity losses in Kerala, India: a model-based analysis
}

\author{
Denny John (D) ," M S Narassima (D) , ${ }^{2}$ Jaideep Menon, ${ }^{1,3}$ Jammy Guru Rajesh, ${ }^{4}$ \\ Amitava Banerjee (i) ${ }^{5}$
}

To cite: John D, Narassima MS, Menon J, et al. Estimation of the economic burden of COVID-19 using disability-adjusted life years (DALYs) and productivity losses in Kerala, India: a modelbased analysis. BMJ Open 2021;11:e049619. doi:10.1136/ bmjopen-2021-049619

- Prepublication history and additional supplemental material for this paper are available online. To view these files, please visit the journal online (http://dx.doi.org/10.1136/ bmjopen-2021-049619).

Received 08 February 2021 Accepted 29 July 2021

Check for updates

(C) Author(s) (or their employer(s)) 2021. Re-use permitted under CC BY-NC. No commercial re-use. See rights and permissions. Published by BMJ.

For numbered affiliations see end of article.

Correspondence to

Dr Denny John;

djohn1976@gmail.com

\section{ABSTRACT}

Objectives From the beginning of the COVID-19

pandemic, clinical practice and research globally have centred on the prevention of transmission and treatment of the disease. The pandemic has had a huge impact on the economy and stressed healthcare systems worldwide. The present study estimates disability-adjusted life years (DALYs), years of potential productive life lost (YPPLL) and cost of productivity lost (CPL) due to premature mortality and absenteeism secondary to COVID-19 in the state of Kerala, India.

Setting Details on sociodemographics, incidence, death, quarantine, recovery time, etc were derived from public sources and the Collective for Open Data DistributionKeralam. The working proportion for 5-year age-gender cohorts and the corresponding life expectancy were obtained from the 2011 Census of India.

Primary and secondary outcome measures The impact of the disease was computed through modelbased analysis on various age-gender cohorts. Sensitivity analysis was conducted by adjusting six variables across 21 scenarios. We present two estimates, one until 15 November 2020 and later updated to 10 June 2021. Results Severity of infection and mortality were higher among the older cohorts, with men being more susceptible than women in most subgroups. DALYs for males and females were 15954.5 and 8638.4 until 15 November 2020, and 83853.0 and 56628.3 until 10 June 2021. The corresponding YPPLL were 1323.57 and 612.31 until 15 November 2020, and 6993.04 and 3811.57 until 10 June 2021, and the CPL (premature mortality) were 263780 579.94 and 41836001.82 until 15 November 2020, and 1 419557903.76 and 278275495.29 until 10 June 2021.

Conclusions Most of the COVID-19 burden was contributed by years of life lost. Losses due to YPPLL were reduced as the impact of COVID-19 infection was lesser among the productive cohorts. The CPL values for individuals aged $40-49$ years old were the highest. These estimates provide the data necessary for policymakers to work on reducing the economic burden of COVID-19 in Kerala.

\section{INTRODUCTION}

Since the first case of COVID-19 was reported in December 2019, COVID-19 has spread

\section{STRENGTHS AND LIMITATIONS OF THIS STUDY}

$\Rightarrow$ This is the first study to characterise the economic burden caused by COVID-19 in the state of Kerala using disability-adjusted life years, years of potential productive life lost and cost of productivity lost.

$\Rightarrow$ The study used publicly sourced data for analysis and presentation of results.

$\Rightarrow$ Exclusion of incidence of cases after 20 August 2020 due to data unavailability could lead to an underestimation of disability-adjusted life years.

$\Rightarrow$ Psychological impacts of mitigation strategies (eg, lockdown, travel restrictions, etc) that could increase mortality were not within the scope of the study.

$\Rightarrow$ Data on unpaid work and presenteeism and on postrecovery illness and the long-term effects of COVID-19 have not been considered.

across all countries, infecting 176705044 people with 3819138 deaths and 160737 654 recoveries worldwide as of 14 June $2021{ }^{1}$ Lower access to quality health facilities in low-income and middle-income countries has placed a sizeable proportion at higher risk. ${ }^{2}$ India ranks second with 29507438 cases and 28148977 recoveries as of 14 June 2021. ${ }^{1}$ Higher infection rates have increased the burden on healthcare systems and thus increased the fatality rate. ${ }^{3}$

Estimating mortality due to COVID-19 helps to understand the dynamics of the pandemic. The role of sociodemographics, social determinants, and geography is important to assess the differential risk levels to the disease with age, gender and geography. ${ }^{4}$ However, indirect effects due to morbidity and postCOVID-19 syndromes have highlighted the far-reaching consequences of the pandemic. ${ }^{5}$ Also, social determinants of health (SDH) often create inequalities between and within territories disproportionately, such as the losses incurred by the caregivers of the 
infected, front-line workers, food insecurity, work-life conditions, unemployment, etc, which have considerable impact on public and health systems. ${ }^{6}$ Governments have imposed strict measures to curtail the morbidity and mortality caused by COVID-19. Individual-level measures such as self-isolation and social distancing and population-level measures such as lockdowns are widely adopted to limit spread. ${ }^{278} \mathrm{SDH}$ plays a vital role in strategising the interventions especially in Lower Middle Income Countries (LMIC), where there are differences in socioeconomic strata. ${ }^{6}$ Quantifying the health and economic impact of COVID-19 would be a reflection of the policy decisions taken. ${ }^{9}$ Economic impact assessment is highly important in countries/territories like India and states such as Kerala, where most of the infected people have recovered.

In India, the first case of COVID-19 was reported in Kerala on 30 January 2020. Timely interventions such as contact tracing, testing, quarantine, isolation and treatment had reduced the spread of the disease in Kerala. ${ }^{10}$ The number of cases in Kerala has now reached 2728 239 with 11181 deaths and 2593625 recoveries as of 13 June 2021. The resulting economic burden of COVID-19 in the state thus appears to be substantial. Therefore, the present study aimed to estimate the economic burden and productivity loss using disability-adjusted life years (DALYs), years of potential productive life lost (YPPLL) and cost of productivity lost (CPL) and their effects on age and gender in the state of Kerala.

\section{METHODS}

\section{Data collection}

The present work is an age-gender cohort-based observational study designed to estimate DALYs and productivity losses due to COVID-19 in Kerala, India. The effect of multimorbidity was considered to estimate the burden of disease $(\mathrm{BoD})$. The human capital approach was adopted to estimate productivity losses. Publicly available data from various sources were used to gather sociodemographic details, information on the incidence, death due to COVID-19, data on quarantine, per capita income, etc for the state of Kerala. ${ }^{11-13}$ The first reported case of COVID-19 in Kerala dates back to 30 January 2020, from when the estimates for the present study have been collected. ${ }^{12} 13$

The 5-year age-gender population of Kerala, the working population in each age-gender cohort and the corresponding life expectancies were obtained from the 2011 Census of India. ${ }^{11}$ Incidence data documented by Team Collective for Open Data Distribution-Keralam (CODD-K) until 20 August 2020 were used to classify the incidence of the age-gender cohorts (online supplemental table SI). Out of 52199 reported cases until 20 August 2020, data on 7645 patients were excluded as they did not have information on age and gender. ${ }^{12}$ Recovery time documented by the team from CODD-K for 1012 patients in Kerala was used. ${ }^{12}$ Data on the number of deaths were extracted from the Government of Kerala dashboard and CODD-K. ${ }^{12}{ }^{13}$ Infections were categorised as mild, moderate and severe/critical. ${ }^{13}{ }^{14}$ Further, estimates updated until 2021 are also presented throughout, all of which will hereon be indicated using subscript '2021'. Table 1 presents the data on various parameters used in the study.

\section{Estimation of the distribution of cases until 10 June 2021}

The distribution of cases for age-gender cohorts in Kerala in 2020 and in India in 2020 and 2021 was used to estimate the distribution of cases in Kerala until 10 June 2021 (online supplemental table SI). The rationale behind the method is that the percentage deviations in the distribution of cases for each age-gender cohort in India then (2020) and now (2021) and those of Kerala are assumed to be the same. In this way, the distribution of cases for age-gender cohorts was computed until 10 June 2021 (online supplemental table SV). The actual number of cases in Kerala as of 10 June 2021 is 2688590 , while our estimates cumulate to 2688516 , with an error of $0.0028 \%$.

\section{Disability-adjusted life years}

DALYs are standard measures to estimate the BoD in public health and are calculated as the sum of years lived with disability (YLD) and years of life lost (YLL) ${ }^{3915}$ DALYs take into account the disability caused by the disease (YLD) and the premature mortality (YLL). ${ }^{9}$ Determining YLLs, YLDs and DALYs would allow us to measure the shortfall of the deceased and life years lost. YLLs explain the loss incurred as a result of death due to an event by comparing it with the years that they would have lived otherwise. YLLs become high in case of either higher mortality or mortality of younger people or both. ${ }^{4}$ YPPLL and CPL are widely adopted measures that mainly explain the economic burden due to an event. ${ }^{16}$

DALYs were calculated using an incidence-based approach. ${ }^{317}$ DALY estimates were obtained for the agegender split to identify the more vulnerable groups. ${ }^{9}$ Although incidence-based approaches do not consider the severity of diseases, due to the diverse impact of COVID-19, severity was considered to assign the disability weight (DW). ${ }^{3}$ Initial estimates of YLDs are presented only until 20 August 2020, and the DALY estimates in this study are certainly an underestimation. However, YLDs contribute only a minor share to the DALY estimates. ${ }^{39} 18$ Discounting for the value of life (discount rate of 2.9\%) was used in the calculation of DALYs. ${ }^{17}$ DALYs with no discounting are also presented in table 2. DWs were chosen based on the symptoms experienced by patients and varied based on the severity of infection. The proportion of home quarantine cases was considered to be mild, while the proportion of hospitalised cases was further split into moderate and critical (table 1 ). The symptoms, the proportion of people experiencing each symptom and the corresponding DWs are presented in online supplemental table SII. ${ }^{19}$ 
Table 1 Parameters used in the study

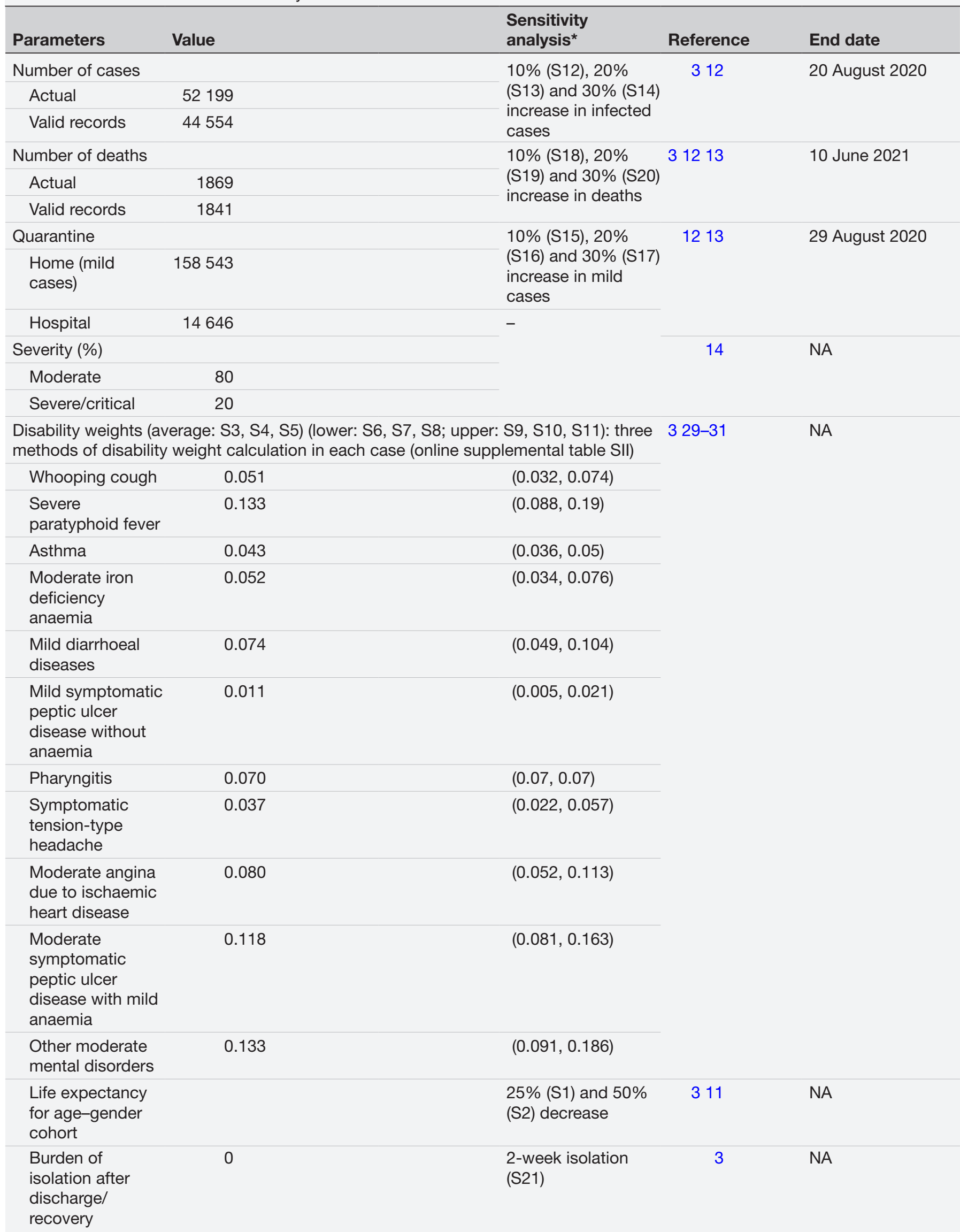


Table 1 Continued

\begin{tabular}{|ccll|}
\hline \multicolumn{2}{|c}{$\begin{array}{l}\text { Value } \\
\text { Parameters }\end{array}$} & $\begin{array}{l}\text { Sensitivity } \\
\text { analysis }\end{array}$ \\
\hline Recovery time for age-gender cohort (duration of disability) & \\
\hline Age group & Time to recovery (days) & Age group & $\begin{array}{l}\text { Time to recovery } \\
\text { (days) }\end{array}$ \\
\hline $0-1$ & 13.00 & 45 to 50 & 13.49 \\
\hline $1-5$ & 17.55 & 50 to 55 & 15.55 \\
\hline $5-10$ & 14.40 & 55 to 60 & 13.57 \\
\hline $10-15$ & 15.59 & 60 to 65 & 13.61 \\
\hline $15-20$ & 13.94 & 65 to 70 & 18.94 \\
\hline $20-25$ & 13.82 & 70 to 75 & 15.00 \\
\hline $25-30$ & 13.16 & 75 to 80 & 11.57 \\
\hline $30-35$ & 14.07 & 80 to 85 & 15.00 \\
\hline $35-40$ & 13.54 & $85+$ & 17.33 \\
\hline $40-45$ & 15.26 & & \\
\hline
\end{tabular}

Reference

End date

12

Available for 1012 patients

11

NA

Female

Age

Male

0-1

72.5

77.9

1-5

72.3

77.8

5-10

68.4

73.9

10-15

63.4

69.0

$15-20$

58.6

64.1

20-25

53.7

25-30

48.9

59.2

54.4

30-35

44.2

49.5

$35-40$

39.5

40-45

34.8

44.7

39.9

45-50

30.3

35.1

50-55

25.9

30.5

55-60

21.8

26.2

60-65

17.9

21.9

65-70

14.3

17.9

11.4

14.3

75-80

8.6

11.0

80-85

6.2

4.5

$85+$

Discount rate for

value of life (\%)

Age-gender population

Online supplemental table

SIII

5.6

2.90

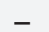

17

NA

Age-gender

working population

\begin{tabular}{llccc}
$\begin{array}{l}\text { Discount } \\
\text { rate (financial } \\
\text { benchmark) (\%) }\end{array}$ & 4.25 & - & 24 & 6 November 2020 \\
\hline $\begin{array}{l}\text { Stay in intensive } \\
\text { care unit (days) }\end{array}$ & 8 & - & 2627 & NA
\end{tabular}

Continued 
Table 1 Continued

\begin{tabular}{|c|c|c|c|c|}
\hline Parameters & Value & $\begin{array}{l}\text { Sensitivity } \\
\text { analysis* }\end{array}$ & Reference & End date \\
\hline $\begin{array}{l}\text { Retirement age in } \\
\text { Kerala (years) }\end{array}$ & 56 & - & 22 & NA \\
\hline $\begin{array}{l}\text { Number of working } \\
\text { days in a week }\end{array}$ & 6 & - & 45 & NA \\
\hline $\begin{array}{l}\text { Per capita gross } \\
\text { domestic product in } \\
\text { Kerala }\end{array}$ & 221904 rupees/year & - & 46 & 2020 \\
\hline
\end{tabular}

$$
Y L D=\frac{I * D W * D\left(1-e^{-r D}\right)}{r}
$$

where $r=$ discount rate; $D=$ disability duration (years); and $I=$ number of incident cases.

$$
Y L L=\frac{N}{r}\left(1-e^{-r L}\right)
$$

where $L=$ life expectancy at age of death (years) and $n=$ number of deaths.

$$
D A L Y=Y L L+Y L D
$$

Most of the BoD studies do not consider multimorbidity, which might yield inaccurate estimates. ${ }^{15}$ Three methods for calculation of combined disability weights (CDW) for multimorbidity as reported by Hilderink $e t a l,{ }^{15}$ viz additive, multiplicative and maximum limit methods, were employed in this study.

$$
D w_{i j}=D W_{i}+D W_{j}
$$

\begin{tabular}{|c|c|c|c|c|c|c|c|c|}
\hline \multirow[b]{3}{*}{ Age } & \multicolumn{4}{|c|}{ DALYs until 15 November 2020} & \multicolumn{4}{|c|}{ DALYs until 10 June 2021} \\
\hline & \multicolumn{2}{|c|}{ Discounted } & \multicolumn{2}{|c|}{ Undiscounted } & \multicolumn{2}{|c|}{ Discounted } & \multicolumn{2}{|c|}{ Undiscounted } \\
\hline & Male & Female & Male & Female & Male & Female & Male & Female \\
\hline $1-5$ & 0.4 & 0.4 & 0.4 & 0.4 & 50.7 & 19.7 & 72.7 & 0.4 \\
\hline $5-10$ & 0.3 & 0.3 & 0.3 & 0.3 & 47.4 & 15.5 & 68.7 & 0.3 \\
\hline $15-20$ & 57.0 & 58.6 & 117.8 & 128.6 & 265.0 & 200.8 & 469.4 & 385.0 \\
\hline $20-25$ & 137.3 & 113.8 & 269.7 & 237.5 & 590.7 & 465.0 & 1021.5 & 888.7 \\
\hline $25-30$ & 262.7 & 192.2 & 490.4 & 381.4 & 893.3 & 639.8 & 1517.3 & 1197.4 \\
\hline 30-35 & 126.0 & 132.0 & 222.4 & 248.1 & 1583.7 & 1168.2 & 2653.4 & 2129.1 \\
\hline $50-55$ & 1603.7 & 952.0 & 2280.2 & 1434.0 & 9240.0 & 5943.5 & 13054.6 & 8906.5 \\
\hline $55-60$ & 2343.5 & 1413.5 & 3161.6 & 2017.8 & 11231.3 & 8078.1 & 15108.0 & 11502.2 \\
\hline $60-65$ & 2639.5 & 1426.8 & 3383.5 & 1927.5 & 13502.1 & 8690.6 & 17273.9 & 11716.8 \\
\hline $65-70$ & 2610.8 & 1089.5 & 3189.4 & 1396.5 & 11711.3 & 7826.5 & 14271.9 & 10006.4 \\
\hline 70-75 & 1669.8 & 983.4 & 1961.0 & 1201.3 & 9513.7 & 6775.0 & 11160.8 & 8265.5 \\
\hline $75-80$ & 898.2 & 508.6 & 1014.8 & 594.0 & 5201.8 & 4080.8 & 5873.8 & 4763.0 \\
\hline $80-85$ & 556.2 & 430.7 & 607.6 & 482.0 & 2908.8 & 2637.2 & 3174.4 & 2946.8 \\
\hline $85+$ & 274.3 & 196.5 & 292.5 & 212.8 & 1428.5 & 1579.8 & 1521.0 & 1708.0 \\
\hline Total & 15954.5 & 8638.4 & 21415.5 & 12241.5 & 83853.0 & 56628.3 & 111607.3 & 78439.5 \\
\hline
\end{tabular}

$$
D W_{i j}=1-\left(1-D W_{i}\right) *\left(1-D w_{j}\right)
$$

Table 2 DALY estimates for the baseline scenario (scenario 3)

DALYs, disability-adjusted life years. 


$$
D W_{i j}=\max \left(D W_{i}, D W_{j}\right)
$$

where ' $i$ ' and ' $j$ ' indicate the DWs of ' $i$ 'th and ' $j$ th disabilities.

\section{Productivity losses (YPPLL and CPL)}

YPPLL is defined as the number of productive years an average person would have lived otherwise. The working population proportion of each cohort was multiplied with the YPPLL to estimate the CPL lost due to morbidity and absenteeism. Recovery days for the severe cases were extended by 8 days to account for intensive care unit (ICU) stay. Productivity losses were estimated using the human capital approach considering absenteeism and premature mortality for temporary and permanent losses, respectively. ${ }^{9}{ }^{20}$ For calculation of productivity losses, people from the age group 15-60 were chosen considering the employment age $\mathrm{e}^{21}$ and retirement age in Kerala. $^{221723}$

$$
Y P P L L=\sum_{i=1}^{n} D_{i} * w_{i} * d \quad \mid \quad i=1,2, \ldots, n
$$

where ' $i$ ' represents ' $n$ ' age-gender cohorts; $D_{i}=$ deaths at age; $w_{i}=$ productive years remaining at age of death (years); and $d=$ discount rate for the value of life as proposed by the Reserve Bank of India. ${ }^{24}$ These are applicable for every year excluding the first year. ${ }^{25}$ CPL for premature mortality and absenteeism was computed as shown in Eqn. (8) and (9).

$$
\begin{gathered}
C P L=\sum_{j=1}^{J} Y P P L L_{j} * \text { per capita } G D P * P \\
C P L_{\text {absenteeism }}=\sum_{j=1}^{J} S * L_{j} * N * P
\end{gathered}
$$

where $S=$ average salary per day considering the number of paid working days per week as six; $L=$ average recovery time; $n=$ number of incident cases; and $P=$ proportion of the working population, in cohort ' $j$ '. For the computation of productivity losses, the proportion of the working population was considered along with an extended disability period for severe cases to account for ICU stay. ${ }^{26} 27$

\section{Sensitivity analysis}

A spectrum of scenarios (online supplemental table SIV) were considered to analyse the effect of each parameter on the DALY estimates. The key idea of performing sensitivity analysis is to assist policymakers in anticipating the effects brought in by each of the driving variables. As most of the deceased cases had underlying health conditions that reduce the life expectancy, scenario 1 and scenario 2 have been developed. ${ }^{48}$ Increasing the number of mild cases, overall cases and deaths is a conservative analysis to help the healthcare fraternity and policymakers. ${ }^{3}$

\section{Validation}

To ensure credibility, data related to COVID-19 (table 1) were collected from various official sources, reports and published works. ${ }^{3}{ }^{11-14} 2627$ 29-31 Discount rates for the financial benchmark and the value of life were taken into account based on the values defined by the Reserve Bank of India ${ }^{24}$ and Shanmugam, ${ }^{17}$ respectively. For the computation of DALY, three different approaches to calculate the CDW as mentioned by Hilderink et $a l^{15}$ were used. The DALY estimates and productivity losses were computed as done by Wyper et $a l^{32}$ and Rumisha et al. ${ }^{33}$

\section{Patient and public involvement}

The data used for inputs and analysis were derived from public sources (such as websites) and published literature. Our research question for estimating the economic burden and productivity losses in Kerala was based on the increase in the number of cases in Kerala from July to November 2020. The increase in the number of cases would also mean increased productivity losses due to COVID-19 for patients and their family members, especially those who died or were hospitalised. However, as our model-based analysis used data from published sources such as publications, websites and modelling methods, patients and/or the public were not involved in the design, or conduct, or reporting or dissemination plans of the research.

\section{Cohort description}

From July 2020 to June 2021 there was a significant increase in the number of COVID-19 cases in Kerala. The increase in the number of cases would also mean increased economic loss due to COVID-19 for patients and their family members, mainly due to the increase in hospitalisations and deaths. We did not involve any patients in the design of this study as we used publicly available sources. However, we aim to disseminate the findings of this paper through various media channels postpublication to reach out to policymakers and the general public in the state of Kerala.

\section{RESULTS}

From the distribution of cases and deaths (online supplemental figure S1, until 15 November 2020; online supplemental figure S2, until 10 June 2021), it is clear that older adults are disproportionately vulnerable to being severely affected by the disease. Although the 25-30 age group of men and women accounts for $13.45 \%$ and $11.06 \%$ of the total number of cases, their proportionate mortality remains as low as $0.80 \%$ and $1.17 \%$, respectively (online supplemental figure S1). Contrastingly, while the male and female proportion of cases for the age group $65-70$ is only $2.11 \%$ and $2.75 \%$ of the overall cases, their proportionate mortality remains as high as $17.88 \%$ and $13.13 \%$, respectively (online supplemental figure S1). The 2021 estimates confirm that the elderly people from the age group 55-70 (online supplemental figure S2) are greatly affected as their proportionate mortality is $39.99 \%$, although their proportionate incidence is as low as $12.34 \%$.

DALY estimates calculated using the average DW scores using the additive method were considered as the baseline 
scenario for sensitivity analysis. From online supplemental table SVI, it is clear that the YLL accounts for the major proportion of DALYs (discounted), with male and female YLL and $\mathrm{YLL}_{2021}$ in the age group 60-65 cumulating to $16.58 \%-16.46 \%$ and $16.21 \%-15.43 \%$, respectively. Since the cohort does not fall into the productive population (considering the employment age), these might not impact productivity losses. Considering the YLLs and DALYs in the productive population, the YLLs and DALYs of men and women are the highest for the age group 55-60. Comparing the discounted and undiscounted DALYs, we see that the undiscounted DALY and DALY ${ }_{2021}$ of males and females are $36.02 \%$ and $44.15 \%$ and $33.1 \%$ and $38.52 \%$ higher than those of the discounted ones. The discount rate for the value of life was considered as $2.90 \%$ for all the scenarios in the study. ${ }^{17}$ Also, DALYs per million and $\mathrm{DALY}_{2021}$ per million were estimated to be 709.2 and 4050.99 based on the projected population of Kerala for the year 2020, which is $34678294 .^{34}$

Online supplemental figure S3A-I and online supplemental figure S4A-I show that overall the DALYs for males are higher than those for females, except for the age groups 30-35, 15-20 and those less than 10. About $47.69 \%$ and $45.34 \%$ of overall DALYs and $43.46 \%$ and

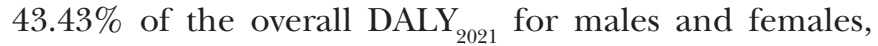
respectively, are from the age group 55-70. It is highly disproportionate as the number of cases from this age group piles up to only $11.13 \%$ and $13.11 \%$ (2020) and $11.32 \%$ and $13.37 \%$ (2021) of cases for men and women, respectively. Online supplemental figures S3 and S4 present the DALYs calculated for the nine different scenarios (refer to online supplemental table SII) that involve altering the DW calculation methods and values.

To measure the impact of the disease on the productivity of the state, YPPLL and CPL were calculated among the productive age group of 15-60 years. The age group 25-49 being the majority is the prime contributor to productivity. Fortunately, the infection has a relatively lesser impact in terms of duration of illness and mortality on this age group, which has reduced the losses to some extent (table 3). Recovery days mentioned in online supplemental table SIII are exclusive of the ICU stay of severe cases.

Table 3 shows that the CPL values for people aged 40-49 years were the highest and constituted about $51.34 \%$ and $41.76 \%$ of the total CPL values (for premature mortality) for men and women, respectively. CPL values for absenteeism are also highest for the same age cohort for both men and women, accounting for up to $26.53 \%$ and $31.35 \%$, respectively. $\mathrm{CPL}_{2021}$ (for premature mortality) gets the highest shares of $58.98 \%$ and $58.73 \%$ from the male and female cohorts of the 41-50 age group (table 4). Similarly, $\mathrm{CPL}_{2021}$ has a maximum of $25.89 \%$ and $30.96 \%$ from the same cohorts, respectively.

\section{Sensitivity analysis}

Figure 1A-F presents the sensitivity analysis explaining the role of each variable in economic burden to provide a better interpretation of the changes and comparison of the DALY estimates across all the scenarios for 2020. Figure 2A-F presents similar results for 2021 estimates. In figure $1 \mathrm{~A}$ it is evident that the reduction in life expectancy by $25 \%$ and $50 \%$ reduced the DALYs by $19.7 \%$ and $42.47 \%$ for males and by $18.78 \%$ and $41.08 \%$ for females, respectively. Likewise, DALY $_{2021}$ reduced by $19.53 \%$ and $42.11 \%$ for males and by $18.89 \%$ and $41.17 \%$ for females, respectively (figure 2A). In figure 1B,C,E and figure 2B,C,E, only YLD values were compared as the variables adjusted in these scenarios do not alter the YLLs. Comparing the DALY estimates might not explain the effect of the variables clearly. In figure 1A,D and figure 2A,D, the DALY estimates were directly compared. Increasing the overall cases by $10 \%, 20 \%$ and $30 \%$ increased the YLDs proportionately equal to the percentage increase in the number of cases. An increase in the mild cases by $10 \%, 20 \%$ and $30 \%$ increased the YLDs by $9.15 \%, 18.31 \%$ and $27.46 \%$, respectively, for both the male and female cohorts. An increase in deaths by $10 \%, 20 \%$ and $30 \%$ increased the DALYs by $9.91 \%, 19.91 \%$ and $29.9 \%$, respectively, for both the male and female cohorts. The increase in the burden of isolation of 2 weeks increased the YLDs from 12.24 to 48.01 for males and from 6.88 to 26.74 for females, and

Table 3 YPPLL and CPL (mortality and absenteeism) until 15 November 2020

\begin{tabular}{|c|c|c|c|c|c|c|}
\hline \multirow[b]{2}{*}{ Age group } & \multicolumn{2}{|l|}{ YPPLL } & \multicolumn{2}{|l|}{ CPL: death } & \multicolumn{2}{|l|}{ CPL: morbidity } \\
\hline & Male & Female & Male & Female & Male & Female \\
\hline $15-19$ & 8.02 & 16.04 & 200004.28 & 144074.81 & 1308538.75 & 325006.38 \\
\hline $25-29$ & 81.38 & 54.25 & 15385047.11 & 2675078.71 & 28999248.30 & 3130470.52 \\
\hline $30-34$ & 46.07 & 46.07 & 9543101.81 & 2934692.41 & 32044805.25 & 4055127.61 \\
\hline $40-49$ & 646.28 & 215.43 & 135448141.17 & 17470735.95 & 48999357.83 & 9131773.54 \\
\hline $50-59$ & 301.17 & 146.91 & 56477423.96 & 9138644.00 & 30872800.27 & 6134611.07 \\
\hline Total & & & 263780579.94 & 41836001.82 & 185026063.37 & 29178488.82 \\
\hline
\end{tabular}

CPL, cost of productivity lost; YPPLL, years of potential productive life lost. 
Table 4 YPPLL and CPL (mortality and absenteeism) until 10 June 2021

\begin{tabular}{|c|c|c|c|c|c|c|}
\hline \multirow[b]{2}{*}{ Age group } & \multicolumn{2}{|l|}{ YPPLL } & \multicolumn{2}{|l|}{ CPL: death } & \multicolumn{2}{|l|}{ CPL: morbidity } \\
\hline & Male & Female & Male & Female & Male & Female \\
\hline $16-20$ & 65.17 & 48.88 & 1625265.52 & 439040.27 & 102297314.03 & 23652339.15 \\
\hline $26-30$ & 282.14 & 200.23 & 53340135.18 & 9872885.34 & 1831188038.59 & 187207907.26 \\
\hline $31-35$ & 552.34 & 395.84 & 114409861.84 & 25214693.78 & 1875906232.92 & 243394778.33 \\
\hline $41-50$ & 3994.98 & 2015.17 & 837278167.58 & 163427668.31 & 2860063434.24 & 541756862.03 \\
\hline $51-59$ & 611.09 & 373.19 & 114596136.95 & 23214211.95 & 1703001999.97 & 350660556.84 \\
\hline Total & & & 1419557903.76 & 278275495.29 & 11047749718.26 & 1749745445.40 \\
\hline
\end{tabular}

Refer to online supplemental table SVII for incidence and deaths.

$\mathrm{CPL}$, cost of productivity lost; YPPLL, years of potential productive life lost.

$\mathrm{YLD}_{2021}$ from 738.82 to 2897.92 for males and from 414.90 to 1612.10 for females.

Three different approaches for the average, lower and upper limit values of DW were used to arrive at YLDs. DALYs are seen to be the highest when the number of deaths is altered. DALYs increase by $29.9 \%$ from that of scenario 3 for both cohorts when the number of deaths increases by $30 \%$. These values would still be higher if mortality among the younger cohorts is high due to their longer life expectancy during the age of death.

\section{DISCUSSION}

\section{Main findings of this study}

In this study, for the baseline scenario, the YLLs were 15942.3 and 8631.6 and the YLDs were 12.2 and 6.9 for males and females. Also, $\mathrm{YLL}_{2021}$ were 83114.1 and 56 213.4 and $\mathrm{YLD}_{2021}$ were 738.8 and 414.9 for males and females. DALYs and DALY 2021 were estimated as 709.2 per million and 4050.99 per million population based on the year 2020 population projections. ${ }^{34}$ However, the DALY estimates will be impacted by the quality of the data reported. Based on an article published by the British Broadcasting Corporation (BBC), the number of deaths due to COVID-19 as estimated by the volunteers is 3356 , which is $70.44 \%$ higher than the officially reported count of 1969 as of 19 November $2020 .{ }^{1335}$ Considering the effect of asymptomatic cases that act as latent spreaders, DWs due to presenteeism and unpaid work could increase the losses. ${ }^{36}$ These facts are concerning as the actual DALYs might be way higher than those estimated using official figures.

The DALY ${ }_{2021}$ estimates sum up to 83853 and 56628.3 for males and females, respectively, indicating a very high impact of the pandemic. $\mathrm{YLL}_{2021}$ were computed at 83 114.1 and 56213.4 for males and females, while $\mathrm{YLD}_{2021}$ were only 738.8 and 414.9 for males and females. Reports state that the second wave has affected the younger population significantly, unlike the first. The distribution of cases among the age groups 21-30, 31-40 and 41-50 until 31 May 2021 was 261 232, 252935 and 233126 people, respectively. Also, $18 \%$ of the people who died in April and May 2021 in the state were not comorbid. ${ }^{37}$

In addition, the productivity losses in terms of YPPLL and CPL for mortality and absenteeism for the productive population (15-60 years of age) were estimated. Multimorbidity was taken into account in the calculation of CDW. CPL values (for premature mortality) for the younger population less than 25 years of age were
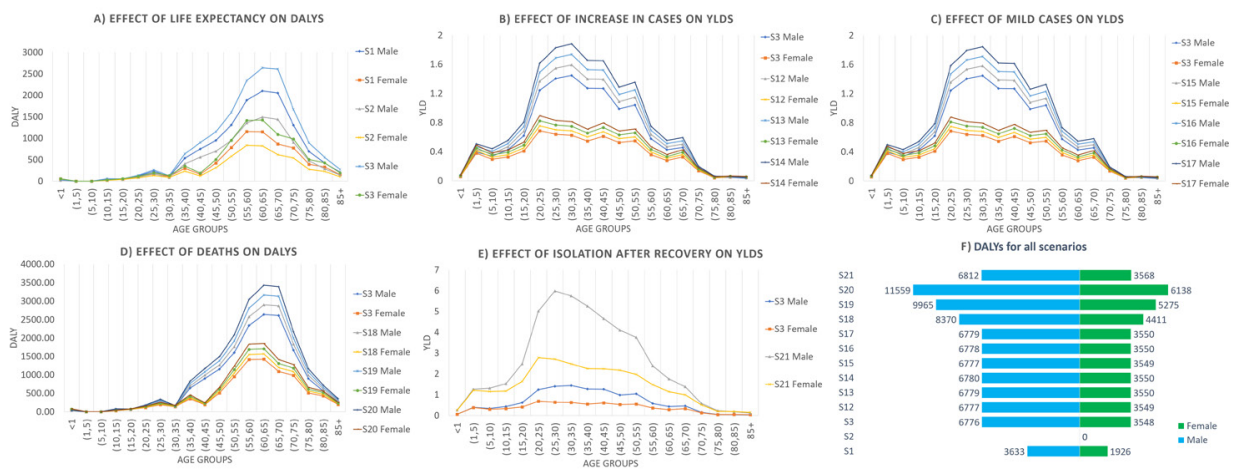

Figure 1 Sensitivity analysis (15 November 2020): (A) effect of life expectancy on DALYs; (B) effect of increase in cases on YLDs; (C) effect of mild cases on YLDs; (D) effect of deaths on DALYs; (E) effect of isolation after recovery on YLDs; and (F) DALYs for all scenarios. DALYs, disability-adjusted life years; YLDs, years lived with disability. 

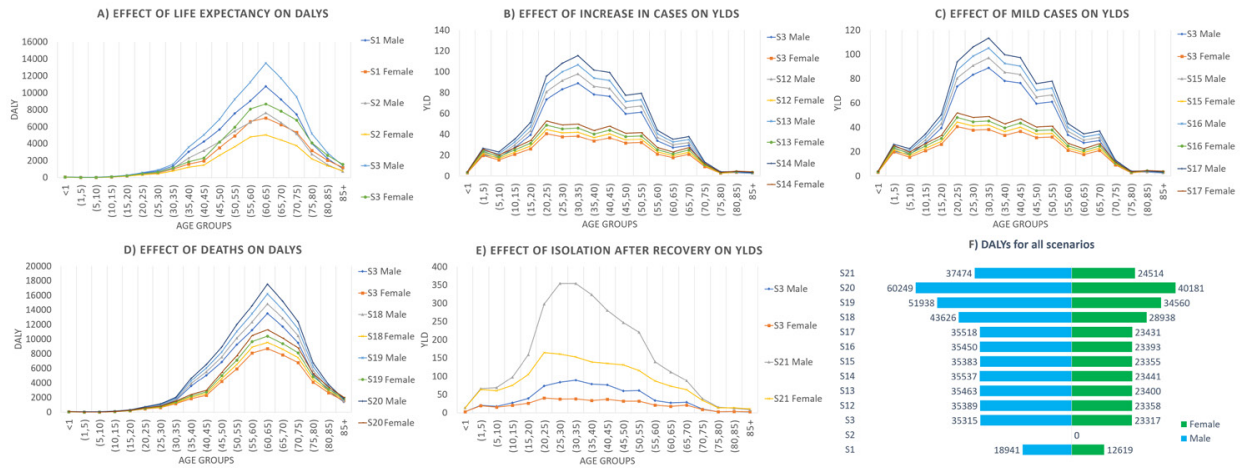

Figure 2 Sensitivity analysis (10 June 2021): (A) effect of life expectancy on DALYs; (B) effect of increase in cases on YLDs; (C) effect of mild cases on YLDs; (D) effect of deaths on DALYs; (E) effect of isolation after recovery on YLDs; and (F) DALYs for all scenarios. DALYs, disability-adjusted life years; YLDs, years lived with disability.

just $1.97 \%$ and $2.37 \%$ for the male and female cohorts, respectively. Likewise, $\mathrm{CPL}_{2021}$ (premature mortality) for the same cohorts constitutes $1.47 \%$ and $1.70 \%$, respectively. This is because of the lesser proportion of people working in this age group and also the lesser impact of the disease in terms of mortality. Considering the CPL due to absenteeism, the values for younger people less than 25 years of age were $8.16 \%$ and $8.83 \%$ for the male and female cohorts, respectively. A similar trend is observed in $\mathrm{CPL}_{2021}$ due to absenteeism, with $8.95 \%$ and $9.36 \%$ contribution from the male and female cohorts less than 25 years of age. This is higher compared with that of deaths due to a relatively lower proportion of people dying due to infection.

\section{What is already known on this topic}

Several researchers have been conducting research to estimate the economic burden and productivity losses of various diseases around the globe, such as the estimation of YLLs due to COVID-19 in the USA, ${ }^{4}$ India ${ }^{18}$ and Switzerland, ${ }^{7}$ DALYs due to COVID-19 in Korea ${ }^{3}$ and Italy, ${ }^{9}$ YPPLL due to cancer in Brazil, Russia, India, China and South Africa, ${ }^{38}$ YPPLL due to the five leading causes of deaths in Iran, ${ }^{16}$ productivity loss due to cardiovascular disease and mental illness in India, ${ }^{36}$ etc. COVID-19 has created a significant impact across the globe, some of which include 1.2 million YLLs in the USA from 1 February 2020 to 11 July $2020^{4}$; 2 million YLL in India as of 17 October $2020^{18} ; 1.75$ million YLLs due to mass confinement of 3 months in Switzerland ${ }^{7}$; 2531 DALYs in Korea between 20 January 2020 and 24 April 2020, with YLLs and YLDs constituting $89.7 \%$ and $10.3 \%$, respectively $^{3}$; and 121449 DALYs and productivity losses of $€ 300$ million and $€ 100$ million due to premature mortality and absenteeism, respectively, in Italy. ${ }^{9}$

\section{What this study adds}

As is evident from this study, the disease has impacted the older population to a greater extent. The proportion of cases for the age group 65-70 in Kerala is only $2.11 \%$ and $2.75 \%$ of the overall cases, while their deaths remain as high as $17.88 \%$ and $13.13 \%$. Other studies reveal a similar trend of the disease, which provides strong insights into providing more care to the elderly. Indrayan and Mishra ${ }^{18}$ found that the relative incidence of the younger age group $(<20)$ was only $1 / 3(12: 36) \%$, whereas those of adults aged more than 60 and between 50 and 59 were $1.5(8: 12) \%$ and 1.88 (14.5:7.7)\%, respectively. ${ }^{18}$ This trend prevails even outside the country, as Garg et $a l^{19}$ concluded that out of 1482 hospitalised patients from 1 March to 28 March 2020 across 14 states of the USA, 3/4 were aged 50 or more.

The age-gender cohort-based study aims to help policymaking in terms of protecting the most vulnerable population from infection. The positive relationship between the Case Fatality Rate (CFR) and the elderly population shows the importance to be accorded for strategies of distribution for both health infrastructure and vaccines, based on population distribution. ${ }^{39}$ There has been a steady drop in CFR in Kerala since the emergence of the disease, ${ }^{13}$ and although multiple variants of the virus have emerged improvements in health infrastructure and therapeutic efforts have been able to keep the CFR abated. This would also decrease the relative contribution of YLLs to the DALYs eventually. Strategies of governance have a vital role to play in curtailing the CFR, and are not limited to political stability, government effectiveness, regulatory quality and control of corruption, with rule of law and voice and accountability having a negative association with the latter. ${ }^{39}$

Sensitivity analysis has been vastly adopted by researchers to depict the influence of one or more variables on the outcome(s). ${ }^{3}{ }^{4}$ A total of 21 scenarios by adjusting six variables were analysed in the study for the 2020 and 2021 estimates. The increase in the number of deaths greatly increased the DALYs, whereas the reduction in life expectancy reduced the DALYs. Reducing life expectancy could be related to the practical findings of the researchers. The majority of older patients have had underlying medical conditions such as pneumonia $(68.8 \%)$, hypertension $(34.4 \%)$, diabetes mellitus (50\%) and chronic obstructive airway disease $(15.6 \%),{ }^{40}$ and $89.3 \%$ of older adults (65 or more) had comorbidities. ${ }^{19}$ 


\section{Limitations of this study}

Exclusion of incidence of cases post 20 August 2020 in the estimation of DALYs due to unavailability of open data has led to a certain underestimation. Also, the psychological impacts of the mitigation strategies are a potential risk that could increase mortality and are not within the scope of the present study. ${ }^{7}$ Most of the policies have not considered mental illness and allied problems. ${ }^{7} 4142$ Although YLDs contribute a minor proportion to DALYs, including factors such as unpaid work and presenteeism might improve the accuracy. In Kerala, about $30 \%$ and $10 \%$ of recovered patients have experienced postrecovery illness and long-term effects, which have not been considered in the study, resulting in an underestimation of YLDs. ${ }^{43}$ Data on the number of deaths from Madhya Pradesh (MP), Andhra Pradesh (AP) and part of Tamilnadu indicate that these estimates could be possible under-reporting, and this might be the case for Kerala as well. ${ }^{44}$ The 'excess deaths' approach shows a clear spike in deaths. In May 2020, MP and AP reported 34320 and 27100 deaths, whereas deaths in May 2021 have reached 164838 and 120845 . Not all of these could be directly attributed to COVID-19 as some relate to deaths due to shortage of oxygen and burden on hospitals. ${ }^{44}$

\section{CONCLUSION}

In conclusion, this is the first study to characterise the economic burden caused by COVID-19 in Kerala using DALYs, YPPLL and CPL. YLL contributed most to the disease burden due to COVID-19. Losses due to YPPLL were reduced as the impact of COVID-19 infection was relatively lesser among the productive age groups. People aged 40-49 years reported the highest CPL values. Decision-makers could use these estimates in order to focus and make efforts on reducing the economic burden and the longer impact of COVID-19 in Kerala.

The methodological framework used in this study can be applied to other states in India and other developing countries where disease notification data are collected by the government and are available in the public domain. Estimation of economic burden using DALYs, YPPLL and CPL attributable to COVID-19 in other states in India and other developing countries could provide the basis for interstate comparison and prioritisation of healthcare resources in resource-limited settings. Subgroup analysis would give deeper insights into the most vulnerable cohorts that require special attention in order to minimise the losses.

\footnotetext{
Author affiliations

${ }^{1}$ Department of Public Health, Amrita Institute of Medical Sciences and Research Centre, Amrita Vishwa Vidyapeetham, Kochi, India

${ }^{2}$ Department of Mechanical Engineering, Amrita School of Engineering, Amrita Vishwa Vidyapeetham, Coimbatore, India

${ }^{3}$ Department of Cardiology, Amrita Institute of Medical Sciences and Research Centre, Amrita Vishwa Vidyapeetham, Kochi, India

${ }^{4}$ Society for Health Allied Research and Education India (SHARE INDIA), Telangana, India
}

${ }^{5}$ Institute of Health Informatics, University College London, London, UK

Twitter Amitava Banerjee @amibanerjee1

Acknowledgements We like to sincerely thank Dr Geetha R Menon, Scientist E, ICMR-National Institute of Medical Statistics, New Delhi, for her comments towards improving this manuscript.

Contributors Conception and design of the study, acquisition of data, or analysis and interpretation of data: DJ, NMS, JM. Drafting the article or revising it critically for important intellectual content: NMS, DJ, JM, JGR, AB. Final approval of the version to be submitted: JM, DJ, JGR, AB.

Funding The authors have not declared a specific grant for this research from any funding agency in the public, commercial or not-for-profit sectors.

Competing interests None declared.

Patient consent for publication Not required.

Ethics approval The study was conducted using publicly available data. No ethical approvals were sought for this study.

Provenance and peer review Not commissioned; externally peer reviewed.

Data availability statement All data relevant to the study are included in the article or uploaded as supplementary information. All data are incorporated into the article and are openly available from the references mentioned.

Supplemental material This content has been supplied by the author(s). It has not been vetted by BMJ Publishing Group Limited (BMJ) and may not have been peer-reviewed. Any opinions or recommendations discussed are solely those of the author(s) and are not endorsed by BMJ. BMJ disclaims all liability and responsibility arising from any reliance placed on the content. Where the content includes any translated material, BMJ does not warrant the accuracy and reliability of the translations (including but not limited to local regulations, clinical guidelines, terminology, drug names and drug dosages), and is not responsible for any error and/or omissions arising from translation and adaptation or otherwise.

Open access This is an open access article distributed in accordance with the Creative Commons Attribution Non Commercial (CC BY-NC 4.0) license, which permits others to distribute, remix, adapt, build upon this work non-commercially, and license their derivative works on different terms, provided the original work is properly cited, appropriate credit is given, any changes made indicated, and the use is non-commercial. See: http://creativecommons.org/licenses/by-nc/4.0/.

\section{ORCID iDs}

Denny John http://orcid.org/0000-0002-4486-632X

M S Narassima http://orcid.org/0000-0002-4113-430X

Amitava Banerjee http://orcid.org/0000-0001-8741-3411

\section{REFERENCES}

1 Worldometer. COVID-19 coronavirus pandemic, 2020.

2 Laxminarayan R, Wahl B, Dudala SR, et al. Epidemiology and transmission dynamics of COVID-19 in two Indian states. Science 2020;370:691-7.

3 Jo MW, Go DS, Kim R, et al. The burden of disease due to COVID-19 in Korea using disability-adjusted life years. J Korean Med Sci 2020;35:1-10.

4 Quast T, Andel R, Gregory S, et al. Years of life lost associated with COVID-19 deaths in the United States. J Public Health 2020;42:717-22.

5 Horton R. Offline: COVID-19 is not a pandemic. Lancet 2020;396:874.

6 WHO. WHO Coronavirus disease 2019 (COVID-19) Situation Report 73, 2020: 1-13.

7 Moser DA, Glaus J, Frangou S, et al. Years of life lost due to the psychosocial consequences of COVID-19 mitigation strategies based on Swiss data. Eur Psychiatry 2020;63:e58.

8 Eubank S, Eckstrand I, Lewis B, et al. Commentary on Ferguson, et al., "Impact of Non-pharmaceutical Interventions (NPIs) to Reduce COVID-19 Mortality and Healthcare Demand". Bull Math Biol 2020;82:52.

9 Nurchis MC, Pascucci D, Sapienza M, et al. Impact of the burden of COVID-19 in Italy: results of disability-adjusted life years (dalys) and productivity loss. Int J Environ Res Public Health 2020;17:4233-12.

10 Menon JC, Rakesh PS, John D, et al. What was right about Kerala's response to the COVID-19 pandemic? BMJ Glob Health 2020;5:e003212. 
11 Office of the Registrar General \& Census Commissioner. Ministry of home Affairs, government of India, 2020.

12 Team CODD-K, 2020. Available: covid19kerala.info

13 C-DIT. GoK Dashboard | official Kerala COVID-19 statistics, 2020.

14 Aylward, Bruce (WHO); Liang W (PRC). Report of the WHO-China joint mission on coronavirus disease 2019 (COVID-19, 2020.

15 Hilderink HBM, Plasmans MHD, Snijders BEP, et al. Accounting for multimorbidity can affect the estimation of the burden of disease: a comparison of approaches. Arch Public Health 2016;74:37.

16 Najafi F, Karami-Matin B, Rezaei S, et al. Productivity costs and years of potential life lost associated with five leading causes of death: evidence from Iran (2006-2010). Med J Islam Repub Iran 2016;30:412.

17 Shanmugam KR. Discount rate for health benefits and the value of life in India. Economics Research International 2011;2011:1-5.

18 Indrayan A, Mishra A. Preliminary estimates of years of life lost (YLL) due to COVID-19 in India. medRxiv2020:1-10.

19 Garg S, Kim L, Whitaker M, et al. Hospitalization Rates and Characteristics of Patients Hospitalized with Laboratory-Confirmed Coronavirus Disease 2019 - COVID-NET, 14 States, March 1-30, 2020. MMWR Morb Mortal Wkly Rep 2020;69:458-64.

20 Kirch W, ed. Human Capital Approach, Encyclopedia of Public Health. Springer, Dordrecht, 2008.

21 India Development Gateway (InDG). Child labour - Vikaspedia, 2020.

22 Kerala Kaumudi Online. Govt mulls extension of retirement age as it considers deferring salary cut plan - Kerala - General, 2020.

23 SISA Research paper. Quantitative Skills - Consultancy for Research and Statistics. Calculating the discounted YPLL annotated.

24 Reserve bank of India. ratios and rates. () Reserv. bank India. all rights Reserv.

25 Michael FD, Mark JS, Karl C. Methods for the economic evaluation of health care programmes. Fourth Edi. Oxford, United Kingdom: Oxford University Press, 2015.

26 Phua J, Weng L, Ling L, et al. Intensive care management of coronavirus disease 2019 (COVID-19): challenges and recommendations. Lancet Respir Med 2020;8:506-17.

27 Rees EM, Nightingale ES, Jafari Y, et al. COVID-19 length of hospital stay: a systematic review and data synthesis. BMC Med 2020;18:270.

28 Hanlon P, Chadwick F, Shah A, et al. COVID-19 - exploring the implications of long-term condition type and extent of multimorbidity on years of life lost: a modelling study. Wellcome Open Res : 2020;5:75.

29 GBD 2015 Mortality and Causes of Death Collaborators. Global, regional, and national life expectancy, all-cause mortality, and causespecific mortality for 249 causes of death, 1980-2015: a systematic analysis for the global burden of disease study 2015. Lancet 2016;388:1459-544.
30 Salomon JA, Haagsma JA, Davis A, et al. Disability weights for the global burden of disease 2013 study. Lancet Glob Health 2015;3:e712-23.

31 Ock M, Lee JY, Oh IH, et al. Disability weights measurement for 228 causes of disease in the Korean burden of disease study 2012. $J$ Korean Med Sci 2016;31 Suppl 2:S129-38.

32 Wyper GMA, Assunção RMA, Colzani E, et al. Burden of disease methods: a guide to calculate COVID-19 Disability-Adjusted life years. Int J Public Health 2021;66:1-7.

33 Rumisha SF, George J, Bwana VM, et al. Years of potential life lost and productivity costs due to premature mortality from six priority diseases in Tanzania, 2006-2015. PLoS One 2020;15:e0234300.

34 Census2011. Kerala population sex ratio in Kerala literacy rate data, 2011-2020.

35 Biswas S. India coronavirus: How a group of volunteers 'exposed' hidden Covid-19 deaths - BBC News. BBC News Serv, 2020.

36 Fathima FN, Kahn JG, Krishnamachari S, et al. Productivity losses among individuals with common mental illness and comorbid cardiovascular disease in rural Karnataka, India. Int $J$ Noncommun Dis 2019;4:86-92.

37 The Hindu. Second wave impacted youth more: Minister - The Hindu, 2021. Available: https://www.thehindu.com/news/national/kerala/ second-wave-impacted-youth-more-minister/article34754237.ece [Accessed 14 Jun 2021]

38 Pearce A, Sharp L, Hanly P, et al. Productivity losses due to premature mortality from cancer in Brazil, Russia, India, China, and South Africa (BRICS): a population-based comparison. Cancer Epidemiol 2018;53:27-34.

39 Farzanegan MR, Feizi M, Gholipour HF. Globalization and the outbreak of COVID-19: an empirical analysis. JRFM 2021;14:105.

40 Aggarwal A, Shrivastava A, Kumar A, et al. Clinical and epidemiological features of SARS-CoV-2 patients in SARI ward of a tertiary care centre in New Delhi. J Assoc Physicians India 2020;68:19-26.

41 Stark L, Ager A. A systematic review of prevalence studies of genderbased violence in complex emergencies. Trauma Violence Abuse 2011:12:127-34.

42 Rendall MS, Weden MM, Favreault MM, et al. The protective effect of marriage for survival: a review and update. Demography 2011;48:481-506.

43 The Hindu. COVID-19| Kerala cm calls for more effective measures for containment, 2020.

44 Yadav Y. What shocking data on Covid second wave deaths really reveals: Yogendra Yadav, 2021. Available: https://theprint.in/opinion/ what-shocking-data-on-covid-second-wave-deaths-really-revealsyogendra-yadav/678890/?fbclid=IwAR3ICQ9pYGunAmztxOtv2V UNESewRcrVckaCuH3cvYIM5keEcdEOtOOk3LE [Accessed 17 Jun 2021].

45 ExcelNotes. Working days in Kerala, India, 2020.

46 MOSPI. Ministry of statistics and program implementation. Gov. India, 2021. Available: http://mospi.nic.in/ [Accessed 13 Mar 2021]. 